\title{
Etiology and Pattern of Mandibular Fractures among Patients Attending Oral and Maxillofacial Surgery Unit in Mulago Hospital, Uganda: A Cross-Sectional Study
}

\author{
Patrick Mpiima, Arabat Kasangaki, Eriab Nkamba, Charles Mugisha Rwenyonyi*
}

Department of Dentistry, School of Health Sciences, College of Health Sciences, Makerere University, Uganda. mrwenyonyi@chs.mak.ac.ug

*Corresponding Author: Charles Mugisha Rwenyonyi, Department of Dentistry, College of Health Sciences, Makerere University, Kampala, Uganda.

\section{Abstract}

Background: The mandible is one of the most commonly fractured bones of the facial skeleton because of its anatomical prominence.

Objective: The objective of the study was to establish the etiological factors and pattern of mandibular fractures among patients ( $n=73$ ) aged 3 - 55 years attending the Oral and Maxillofacial Surgery Unit of Mulago Hospital.

Methods: This was a hospital based cross-sectional study among patients with mandibular fractures who were consecutively recruited after informed consent. The data were collected using a structured questionnaire and clinical oral examination. The collected data were analyzed using Statistical Package for Social Sciences, version 17 for Windows, Chicago, Illinois, USA.

Results: There were 73 patients with 107 mandibular fracture sites. Most fractures were caused by road traffic accident (58\%) and assault (38\%), and especially among pedestrians and passengers. About half of the patients with fractures were aged 21-30 years. The sex ratio of the patients was 7.7 males versus 1 female. About 17\% of the patients were under the influence of alcohol during injury. Majority (69.9\%) of the injuries occurred in the Kampala Metropolitan area. Single fractures were observed in 55\% of the patients and half of them, displaced. About $91 \%$ of the patients with multiple fractures were bilateral. Conclusions: The present study indicated that road traffic accidents and assaults were major causes of madibular fractures, particularly among the youths in the studied population. Males were more prone to mandibular fractures.

Keywords: assaults, pedestrians, mandibular fractures, road traffic accidents

\section{INTRODUCTION}

The mandible (lower jaw) is the largest and strongest bone of the face. It houses the lower teeth and plays a role in mastication, respiration, speaking, swallowing and facial aesthetics. It consists of a curved or horse shoe shaped horizontal body, and two perpendicular rami, which unite with the two ends of the body almost at right angles ${ }^{1}$. The mandible is an anatomically prominent and mobile component of the facial skeleton that is the most commonly fractured bone of the face ${ }^{2,3}$. The various mandibular fracture patterns (types) are based on anatomic sites, ${ }^{3-5}$ which include: alveolar ridge (process), symphysis, parasymphysis, body, angle, ramus, condyle, and coronoid ${ }^{3}$ (Table 1). Some of the mandibular fractures are either single/ multiple or unilateral/bilateral, ${ }^{6,7}$ comminuted or displaced in nature ${ }^{8,9}$. 
Etiology and Pattern of Mandibular Fractures among Patients Attending Oral and Maxillofacial Surgery Unit in Mulago Hospital, Uganda: A Cross-Sectional Study

Table 1. Classification of mandibular fractures according to anatomic site of the bone ${ }^{1}$

\begin{tabular}{|l|l|}
\hline Anatomic site & Description of fracture \\
\hline Alveolar ridge & $\begin{array}{l}\text { Limited to the tooth bearing area of the mandible without disrupting the continuity of the } \\
\text { underlying osseous structure }\end{array}$ \\
\hline Symphysis & $\begin{array}{l}\text { Occurs in the region of the incisors running from the alveolar ridge through the inferior } \\
\text { boarder of the mandible }\end{array}$ \\
\hline Parasymphysis & $\begin{array}{l}\text { Occurs between the mental foramen and the distal aspect of the lateral incisor extending } \\
\text { from alveolar ridge through the inferior boarder }\end{array}$ \\
\hline Body & $\begin{array}{l}\text { Occurs in region between the mental foramen and the distal portion of the second molar, } \\
\text { exceeding from the alveolar ridge through the inferior boarder. }\end{array}$ \\
\hline Angle & $\begin{array}{l}\text { Occurs distal to the second molar, extending from any point on the curve formed by the } \\
\text { junction of the body and ramus in the retro molar area to any point on the curve formed by } \\
\text { the inferior boarder of the body and the posterior boarder of the ramus }\end{array}$ \\
\hline Ramus & $\begin{array}{l}\text { One with fracture line that extends horizontally through the anterior and posterior boarders } \\
\text { of the ramus vertically from the sigmoid notch to the inferior boarder of the mandible }\end{array}$ \\
\hline Condyle & $\begin{array}{l}\text { Fracture runs from the sigmoid notch to the posterior boarder of the ramus of the mandible } \\
\text { along the superior aspect of the ramus }\end{array}$ \\
\hline
\end{tabular}

Khan et al. $^{10}$ noted that the fracture site of the mandible depends on the magnitude and direction of the impact force. They indicated that the mandible tends to fracture at the site of high tensile strain and is more sensitive to lateral impact especially at the body and ramus. The frequency of mandibular fractures increased with age, exacerbated by atrophy. Apart from age, presence of teeth in the mandible and the magnitude of the force had direct effect on the characteristics of the resulting fracture ${ }^{10}$.

Previous surveys ${ }^{11-13}$ on mandibular fractures showed that the etiology varies from one country to another and within the same country depending on prevailing socio-economic, cultural, religious and environmental factors as well as time of the day. The most common etiological factors are road traffic accidents (RTA), falls, gunshots, sporting activities and industrial accidents ${ }^{14}$. Generally, assault is the predominant cause of maxillofacial fractures in developed countries while motor vehicle accidents are the most prevalent in developing countries ${ }^{15,16}$.

In Uganda, Kamulegeya et al. ${ }^{17}$ reported $68.9 \%$ of isolated mandibular fractures among patients with maxillofacial fractures who attended Mulago Hospital. More than half of the mandibular fractures were due to RTA .The male to female ratio was 7.7:1 and the 21-30 year age group was most affected. The fracture pattern of the mandible was either single or multiple and unilateral or bilateral with or without displacement or comminution. Although, Kamulegeya et al. ${ }^{17}$ gave baseline data on mandibular fractures in
Mulago Hospital, they did not report on some of the fracture sites, indicative of limited information, hence the purpose of the present study to elaborate more on the subject.

\section{METHODOLOGY}

\section{Study Design}

This was a descriptive cross sectional study based on consecutive recruitment of participants.

\section{Study Setting}

The study was carried out at Oral and Maxillofacial Surgery (OMFS) unit in Mulago Hospital. The hospital is a national referral and teaching hospital located in Kampala, the capital city of Uganda. It has several outpatient clinics and wards with more than 1500 bed capacity. The OMFS unit has an outpatient clinic and a 22 bed ward. It has a team of various categories of oral health workers including Oral and Maxillofacial Surgeons, a Radiologist, Senior House Officers, Dental Surgeons, Interns and Nurses. Maxillofacial patients are routinely received through the hospital Causality Department and depending on their condition, they are sent either to the outpatients' clinic or the ward for appropriate management.

\section{Study Popullation}

The study participants comprised of male and female patients aged 3 - 55 years with mandibular fractures, consecutively selected from all newly registered patients attending the OMFS clinic in Mulago Hospital.

Archives of Dentistry and Oral Health V1 . I1 . 2018 
Etiology and Pattern of Mandibular Fractures among Patients Attending Oral and Maxillofacial Surgery Unit in Mulago Hospital, Uganda: A Cross-Sectional Study

\section{Inclusion Criteria}

All newly registered patients with mandibular fractures due to trauma.

\section{Exclusion Criteria}

Patients with mandibular fractures who on their own or attendants could not recall the history or circumstances of the injury.

\section{Selection of Study Participants}

The sample size $(n=73)$ was determined based on the estimated $5 \%$ prevalence of mandibular fractures from medical records in OMFS unit in Mulago Hospital (Mpiima 2016, unpublished) and using Kish ${ }^{18}$ formular. The patients with mandibular fractures who met the inclusion criteria were consecutively recruited after written informed consent.

\section{Data Collection}

The demographic information: aetiological and risk factors associated with mandibular fractures were recorded using a structured questionnaire through an oral interview of the patient/parent/guardian and review of medical records. The pattern of mandibular fractures was recorded through clinical oral examination of the patient by the Principal Investigator (PM). Radiographs that were routinely requested by the attending surgeons were used to confirm the pattern of mandibular fractures with help of an Oral and Maxillofacial Radiologist (Kate Kabenge).

\section{QuAlity ConTrol}

The clinical examiner (PM) was a trained dentist previously calibrated in recording mandibular fracturesbya ConsultantOral and MaxillofacialSurgeon (Francis Lakor). The filled data collection forms were double checked for errors and completeness before the patient was dismissed. The data were entered into computer and double checked for errors and completeness.

\section{Data Management and Analysis}

The data were entered into computer and analyzed using Statistical Package for Social Sciences (SPSS) Inc. version 17 for windows, Chicago, Illinois, USA. Descriptive statistics were used to summarize the data and presented in tables.

\section{Ethical Consideration}

The study was approved by Makerere University School of Health Sciences Research and Ethics Review Board, Mulago Hospital Research and Ethics Committee and Uganda National Council of Science and Technology. The patients who were 18 years and above were requested for written informed consent in accordance with Helsinki Declaration ${ }^{19}$. For patients aged between 12 and 17 years, were requested for assent in addition to the consent from their parents or guardians, while those below 12 years, had their informed consent obtained from parents or guardians. A local language (Luganda) version of consent form was used for the patients/guardians who did not understand English. In the event that one was illiterate, s/he was requested to thumb print after an explanation to her/ him what the study was all about. The information obtained from the participants was kept confidential apart from sharing it with the attending health care providers. There were no personal identifiers of the patients like names during data collection and the findings remained anonymous.

\section{RESULTS}

\section{Demographic Characteristics of Patients with} Mandibular Fractures

Majority (88\%) of the patients were males (Table 2). Most patients $(48 \%, \mathrm{n}=35)$ were in the $21-30$ year age group while $28.8 \%$ were aged $\leq 20$ years Table 2 ). Majority (44\%) of the patients had attained secondary level education and only $1 \%$ had informal education. Most patients with mandibular fractures were pedestrians $(39.7 \%)$ and motor cyclists $(23 \%$; Table 2). The majority (38\%) of the patients had fractures between $9.01 \mathrm{pm}$ and $5.59 \mathrm{am}$. About 53.6\% (n=15) of the patients who got injuries between 9:01 pm and 5:59 pm was due to assault.

\section{Aetiological and Risk Factors of Mandibular} Fractures

Road traffic accidents (57.5\%) and assault (38.4\%) were the most common causes of mandibular fractures (Table 2). Majority of the patients (85\%, $n=62$ ) attained the mandibular fractures from the central region (Table 2) and Kampala Metropolitan area alone (Kampala, Wakiso and Mukono) had 
Etiology and Pattern of Mandibular Fractures among Patients Attending Oral and Maxillofacial Surgery Unit in Mulago Hospital, Uganda: A Cross-Sectional Study

$69.86 \%$ ( $n=51$; Table 2) of the burden. In Northern region, the 3 patients with mandibular fractures were respectively, due to RTA, gunshot and assault (Table 2). In Eastern region, the 2 patients with mandibular fractures were due to RTA (Tables 1\&2) and in Southern region, no patient was observed. About $19 \%(n=14)$ of the patients reported substance abuse, particularly alcohol (Table 2). Most patients (83.3\%) who abused alcohol sustained mandibular fractures following assault. The patient who abused khat got the fracture in RTA unlike the marijuana counterpart, due to assault. One patient had seizures at the time of the injury and due to RTA (Table 2).

Table 2. The frequency distribution of patients with mandibular fractures according to demographic factors and cause of injury ( $n=73$ )

\begin{tabular}{|c|c|c|c|c|c|c|}
\hline \multirow{2}{*}{\multicolumn{2}{|c|}{ Demographic factor }} & \multicolumn{5}{|c|}{ Cause of injury } \\
\hline & & \multirow{2}{*}{\begin{tabular}{|l|} 
RTA n (\%) \\
$35(54.0)$ \\
\end{tabular}} & \multirow{2}{*}{\begin{tabular}{|l|}
$\begin{array}{l}\text { Sports } \\
\text { activity n (\%) }\end{array}$ \\
$1(1.5)$
\end{tabular}} & \multirow{2}{*}{\begin{tabular}{|l|} 
Gunshot n(\%) \\
$1(1.5)$
\end{tabular}} & \multirow{2}{*}{\begin{tabular}{|l} 
Fall n(\%) \\
$1(1.5)$
\end{tabular}} & \multirow{2}{*}{\begin{tabular}{|l|} 
Assault n (\%) \\
$26(40.7)$
\end{tabular}} \\
\hline Sex & Male & & & & & \\
\hline & Female & $7(77.8)$ & $0(0.0)$ & $0(0.0)$ & $0(0.0)$ & $2(22.2)$ \\
\hline \multirow[t]{3}{*}{ Age (Years) } & $\leq 20$ & 13(61.90) & $1(4.76)$ & $0(0.0)$ & $1(4.76)$ & $6(28.57)$ \\
\hline & $21-30$ & 18(51.43) & $0(0.0)$ & $0(0.0)$ & $0(0.0)$ & $17(48.57)$ \\
\hline & $>30$ & $11(64.70)$ & $0(0.0)$ & $1(5.88)$ & $0(0.0)$ & $5(29.41)$ \\
\hline \multirow[t]{4}{*}{ Educational level } & Informal & $1(100)$ & $0(0.0)$ & $0(0.0)$ & $0(0.0)$ & $0(0.0)$ \\
\hline & Primary & $19(73.07)$ & $0(0.0)$ & $0(0.0)$ & $1(3.85)$ & $6(23.08)$ \\
\hline & Secondary & $16(50)$ & $1(3.13)$ & $1(3.13)$ & $0(0.0)$ & $14(43.75)$ \\
\hline & Tertiary & $6(42.86)$ & $0(0.0)$ & $0(0.0)$ & $0(0.0)$ & $8(57.14)$ \\
\hline \multirow{3}{*}{$\begin{array}{l}\text { Substance abuse } \\
(\mathrm{n}=14)\end{array}$} & Alcohol & $2(16.70)$ & $0(0.0)$ & $0(0.0)$ & $0(0.0)$ & $10(83.30)$ \\
\hline & Marijuana & $0(0.0)$ & $0(0.0)$ & $0(0.0)$ & $0(0.0)$ & $1(100)$ \\
\hline & Khat & $1(100)$ & $0(0.0)$ & $0(0.0)$ & $0(0.0)$ & $0(0.0)$ \\
\hline \multirow{6}{*}{$\begin{array}{l}\text { Role of } \\
\text { participant at } \\
\text { time of injury }\end{array}$} & Pedestrian & $8(27.59)$ & $0(0.0)$ & $0(0.0)$ & $0(0.0)$ & $21(72.41)$ \\
\hline & Passenger & $17(100)$ & $0(0.0)$ & $0(0.0)$ & $0(0.0)$ & $0(0.0)$ \\
\hline & Motorcyclist & $13(76.47)$ & $0(0.0)$ & $0(0.0)$ & $0(0.0)$ & $4(23.53)$ \\
\hline & Bicyclist & $3(100)$ & $0(0.0)$ & $0(0.0)$ & $0(0.0)$ & $0(0.0)$ \\
\hline & Driver & $1(100)$ & $0(0.0)$ & $0(0.0)$ & $0(0.0)$ & $0(0.0)$ \\
\hline & Other & $0(0.0)$ & $1(16.67)$ & $1(16.67)$ & $1(16.67)$ & $3(50)$ \\
\hline \multirow{3}{*}{$\begin{array}{l}\text { Timeof } \\
\text { attainment of } \\
\text { injury }\end{array}$} & 6:00am-4:00pm & $17(77.27)$ & $0(0.0)$ & $0(0.0)$ & $0(0.0)$ & $5(22.73)$ \\
\hline & 4:01-9:00pm & $13(56.52)$ & $1(4.35)$ & $1(4.35)$ & $0(0.0)$ & $8(34.78)$ \\
\hline & 9:01- 5:59am & $12(42.86)$ & $0(0.0)$ & $0(0.0)$ & $1(3.57)$ & 15(53.57) \\
\hline \multirow{5}{*}{$\begin{array}{l}\text { Place of } \\
\text { attainment of } \\
\text { injury }\end{array}$} & Central region & $34(54.84)$ & $1(11.61)$ & $0(0.0)$ & $1(1.61)$ & $26(41.94)$ \\
\hline & Western region & $5(83)$ & $0(0.0)$ & $0(0.0)$ & $0(0.0)$ & $1(17)$ \\
\hline & \begin{tabular}{|l|} 
Eastern region \\
\end{tabular} & $2(100)$ & $0(0.0)$ & $0(0.0)$ & $0(0.0)$ & $0(0.0)$ \\
\hline & Northern region & $1(33.33)$ & $0(0.0)$ & $1(33.33)$ & $0(0.0)$ & $1(33.33)$ \\
\hline & Southern region & $0(0.0)$ & $0(0.0)$ & $0(0.0)$ & $0(0.0)$ & $0(0.0)$ \\
\hline
\end{tabular}

\section{Pattern of Mandibular Fractures}

Forty (54.8\%) of the patients had single mandibular fractures with a displacement in $50 \%$ of them (Table
3). Comminuted fractures were observed in 2 (5\%) of the patients with single mandibular fractures in the body and angle of the mandible (Table 3). 
Etiology and Pattern of Mandibular Fractures among Patients Attending Oral and Maxillofacial Surgery Unit in Mulago Hospital, Uganda: A Cross-Sectional Study

Table 3. The frequency distribution of patients with single mandibular fractures according to anatomic site, displaced and comminuted fractures $(n=40)$

\begin{tabular}{|l|l|l|l|l|}
\hline Fracture site & \multicolumn{2}{l|}{ Displaced fractures, $\mathrm{n}(\%)$} & \multicolumn{2}{l|}{ Comminuted fractures, $\mathrm{n}(\%)$} \\
\hline & Yes & No & Yes & No \\
\hline Dento-alveolar & $4(20.0)$ & $2(10.0)$ & $0(0.0)$ & $6(15.78)$ \\
\hline Symphysis & $4(20,0)$ & $2(20,0)$ & $0(0.0)$ & $6(15.78)$ \\
\hline Parasymphysis & $3(15.0)$ & $6(30.0)$ & $0(0.0)$ & $9(23.68)$ \\
\hline Body & $3(15.0)$ & $7(35.0)$ & $1(50.0)$ & $9(23.68)$ \\
\hline Angle & $3(15.0)$ & $3(15.0)$ & $1(50.0)$ & $5(13.16)$ \\
\hline Ramus & $0(0.0)$ & $0(0.0)$ & $0(0.0)$ & $0(0.0)$ \\
\hline Condyle & $3(15.0)$ & $0(0.0)$ & $0(0.0)$ & $3(7.89)$ \\
\hline Coronoid & $0(0.0)$ & $0(0.0)$ & $0(0.0)$ & $0(0.0)$ \\
\hline Total & $20(50.0)$ & $20(50.0)$ & $2(5.0)$ & $38(95.0)$ \\
\hline
\end{tabular}

Thirty three $(45 \%)$ of the patients had multiple of the patients with multiple mandibular fractures mandibular fractures, 27 of them with displacement (Table 4). Six percent $(n=2)$ of the multiple fractures were comminuted in the combination of the symphysis and condyle as well as the parasymphysis and the angle of the mandible. Ninety one percent $(n=30)$ were bilateral (Table 4). The most common fracture combination $(33 \%, \mathrm{n}=10)$ was involving the body and angle of the mandible, and were non-comminuted (Table 4).

Table 4. The frequency distribution of patients with multiple mandibular fractures according to anatomic site, displaced or comminuted fractures and bilaterality ( $n=33)$

\begin{tabular}{|c|c|c|c|c|c|c|}
\hline \multirow[b]{2}{*}{$\begin{array}{l}\text { Fracture } \\
\text { combination }\end{array}$} & \multicolumn{2}{|c|}{ Displaced fractures, n (\%) } & \multicolumn{2}{|c|}{ Comminuted fractures, n (\%) } & \multicolumn{2}{|c|}{ Bilaterality, n (\%) } \\
\hline & Yes & No & Yes & No & Unilateral & Bilateral \\
\hline $\mathrm{S}+\mathrm{D} / \mathrm{A}$ & $1(3.7)$ & $0(0.0)$ & $0(0.0)$ & $1(3.2)$ & $1(33.3)$ & $0(0.0)$ \\
\hline $\mathrm{S}+\mathrm{A}$ & $1(3.7)$ & $1(16)$ & $0(0.0)$ & $2(6.5)$ & $0(0.0)$ & $2(6.7)$ \\
\hline $\mathrm{S}+\mathrm{P}$ & $1(3.7)$ & $0(0.0)$ & $0(0.0)$ & $1(3.2)$ & $0(0.0)$ & $1(3.3)$ \\
\hline $\mathrm{S}+\mathrm{C}$ & $2(7.1)$ & $0(0.0)$ & $1(50.0)$ & $1(3.2)$ & $0(0.0)$ & $2(6.7)$ \\
\hline $\mathrm{S}+\mathrm{A}+\mathrm{C}$ & $1(3.7)$ & $0(0.0)$ & $0(0.0)$ & $1(3.2)$ & $0(0.0)$ & $1(3.3)$ \\
\hline $\mathrm{S}+\mathrm{B}$ & $1(3.7)$ & $1(16)$ & $0(0.0)$ & $2(6.5)$ & $0(0.0)$ & $2(6.7)$ \\
\hline $\mathrm{P}+\mathrm{A}$ & $3(11)$ & $0(0.0)$ & $1(50.0)$ & $2(6.5)$ & $0(0.0)$ & $3(10)$ \\
\hline $\mathrm{P}+\mathrm{B}$ & $3(11)$ & $0(0.0)$ & $0(0.0)$ & $3(10)$ & $0(0.0)$ & $3(10)$ \\
\hline $\mathrm{P}+\mathrm{B}+\mathrm{C}$ & $1(3.7)$ & $0(0.0)$ & $0(0.0)$ & $1(3.2)$ & $0(0.0)$ & $1(3.3)$ \\
\hline $\mathrm{B}+\mathrm{A}$ & $7(26)$ & $3(50)$ & $0(0.0)$ & $10(32.0)$ & $0(0.0)$ & $10(33.0)$ \\
\hline $\mathrm{B}+\mathrm{B}$ & $5(19)$ & $1(16)$ & $0(0.0)$ & $6(19.3)$ & $1(33.3)$ & $5(17.0)$ \\
\hline $\mathrm{B}+\mathrm{R}$ & $1(3.7)$ & $0(0.0)$ & $0(0.0)$ & $1(3.2)$ & $1(33.3)$ & $0(0.0)$ \\
\hline Total & $27(82.0)$ & $6(18)$ & $2(6.0)$ & $31(94.0)$ & $3(9.0)$ & $30(91.0)$ \\
\hline
\end{tabular}

$\mathrm{S}=$ symphysis, $\mathrm{D} / \mathrm{A}=$ dento- alveolar, $\mathrm{P}=$ parasymphysis, $\mathrm{B}=$ body, $\mathrm{A}=$ angle, $\mathrm{R}=$ ramus, $\mathrm{C}=$ condyle. 
Etiology and Pattern of Mandibular Fractures among Patients Attending Oral and Maxillofacial Surgery Unit in Mulago Hospital, Uganda: A Cross-Sectional Study

\section{DiscUSSION}

The present study comprised of consecutively recruited patients $(n=73)$ aged 3 to 55 years with mandibular fractures attending Oral and Maxillofacial Surgery unit in Mulago Hospital. It was not possible to randomly select the study participants because of low numbers of victims with mandibular fractures attending the health facility, implying that the findings of the study may not be extrapolated to represent the general population.

Generally, the most common causes of mandibular fractures were RTA and assault, which is in agreement with previous studies in United Arab Emirates ${ }^{20}$ and Pakistan ${ }^{14}$. However, RTA was a more frequent cause of mandibular fractures as compared to assault (Table 2) similar to what was earlier observed in Uganda ${ }^{17}$ and other developing countries ${ }^{15,21,22}$.

Apart from RTA and assault, other causes like falls $^{11,12}$, gunshots ${ }^{23}$, were not prevalent in the present study, which supports the notion that the causes of mandibular fractures tend to vary with geographical region, socioeconomic status, culture, religion and time of the day ${ }^{11-13,24}$.

In the present study, most patients with mandibular fractures were aged 30 years or less, which is consistent with previous studies ${ }^{17,24-26}$. It could be hypothesized that the second and third decades of life are the most active period leading to higher vulnerability to traumatic injuries. The male to female ratio was about 8:1, which corroborates findings from previous studies in Uganda ${ }^{17}$, United States of America ${ }^{2}$, and Lithuania $^{24}$ and India ${ }^{25}$. The reason for the observed high male to female ratio is not obvious, but it could be assumed to be due to gender based activities; males being more involved in risky adventures such as riding motorcycles, driving vehicles, fighting and jobs involving climbing.

In the present study, alcohol consumption contributed about $16 \%$ of mandibular fractures (Table 2) compared to $79 \% \%$ in Thailand $^{8}, 29 \%$ in Canada ${ }^{9}$ and $21 \%$ in Philippines ${ }^{23}$. However, in an earlier study ${ }^{17}$ in Uganda, all the respondents $(n=87)$ denied any influence of alcohol at the time of attaining the injuries. Similarly, there was no reported influence of alcohol on mandibular fractures in Iran ${ }^{27}$ probably because alcohol is outlawed in Islamic countries. Among alcohol abusers, $83.3 \%$ of patients sustained mandibular fractures following assault (Table 2). This value is higher than $65 \%$ recorded in Johannesburg ${ }^{28}$ and $37 \%$ in Canada 9 .

In the present study, most of the patients who sustained mandibular fractures following RTA were pedestrians, passengers or motorcyclists (Table 2). However, there is no similar previous study to which this finding could be compared. We observed majority (70\%) of the fractures were attained in the evening and at night, comparable to $60 \%$ reported in Lithuania ${ }^{24}$, This could be due to poor visibility at night leading to accidents and the use of the cover of darkness by assailants.

Most of the patients came from the central region of Uganda (Table 2) and more so the Kampala Metropolitan area probably because of proximity to the site of study. In the Uganda Police Force Report of 2007-2011, the majority of the accidents occurred in the Kampala Metropolitan area due to the rapid increase in population and road traffic, especially the use of commercial motorcycles (Boda-Bodas).

Overall, in the present study, the body of the mandible was the most commonly fractured site while there was no observed fracture involving the coronoid. This finding was consistent with the observation in Brazil ${ }^{7}$. About a third of the fractures were involving the symphysis and parasymphysis which compares with findings in a Canadian study ${ }^{9}$, but lower than $45.3 \%$ of parasymphysial fractures seen in Thailaland ${ }^{8}$.

The Condyle fractures were seen in $6.5 \%$ of the patients (Table 3), which is much lower than $42 \%$ in German ${ }^{29}$ and 34\% in India ${ }^{30}$. We recorded 6.5\% of patients with dental alveolar fractures, which was slightly lower that $7.4 \%$ seen in Brazil ${ }^{7}$. About half (55\%) of the patients had single fractures (Table 3) compared to $40 \%$ recorded in Canada ${ }^{9}, 52 \%$ in Brazil $^{7}$ and $75.5 \%$ in Kenya ${ }^{6}$.

\section{ConClusion}

The present study indicated that road traffic accidents and assaults were major causes of madibular fractures, particularly among the youths in the study population. Males were more prone to mandibular fractures.

\section{RECOMMENDATIONS}

There is a need to reduce the causes of mandibular fractures such as enforcement of rules and regulations regarding traffic and alcohol consumption especially among the male youths. 
Etiology and Pattern of Mandibular Fractures among Patients Attending Oral and Maxillofacial Surgery Unit in Mulago Hospital, Uganda: A Cross-Sectional Study

\section{REFERENCES}

[1] O'Meara C, Witherspoon R, Hapangama N, Hyam DM. Mandible fracture severity may be increased by alcohol and interpersonal violence. Aust Dent J 2011; 56(2): 166-70

[2] Ogundare BO, Bonnick A, Bayley N. Pattern of mandibular fractures in an urban major trauma center. J Oral Maxillofac Surg 2003; 61(6): 713-8.

[3] Miloro M. Peterson's Principles of Oral and Maxillofacial Surgery, $2^{\text {nd }}$ ed. DC Decker Inc, Hamilton London, 2004. p. 402-31.

[4] de Matos FP, Arnez MF, Sverzut CE, Trivellato AE. A retrospective study of mandibular fractures in a 40-month period. Int J Oral Maxillofac Surg 2010; 39(1): 10-5

[5] Park JM, Jang YW, Kim SG, Park YW, Rotaru H, Baciut G. Comparative study of the prognosis of an extracorporeal reduction and a closed treatment in mandibular condyle head and/ or neck fractures. J Oral Maxillofac Surg 2010; 68(12): 2986-93.

[6] Mwaniki DL, Guthua SW. Occurrence and Characteristics of mandibular fractures in Nairobi, Kenya. Br J Oral Maxillofac Surg 1990; 28(3): 200-2.

[7] Martin MZ, Takahashi A, de Oliveira Nato HG, de Caravalho Jr. JP, Curcio R, Shinohara EH. Epidemiology of mandibular fractures treated in a Brazilian level I Trauma Public Hospital in the city of São Paulo. Brazil. Braz Dent J 2006; 17(3): 103-13.

[8] SirimaharajW,PyungtanasupK.Theepidemiology of mandibular fractures treated at Chiang Mai University Hospital: A review of 198 cases. J Med Assoc Thai 2008; 91(6): 868-74.

[9] Czerwinski M, Parker WL, Chehade A, Williams HB. Identification of mandibular fracture epidemiology in Canada. Enhancing injury prevention and patient evaluation. Canad J Plast Surg 2008; 16(1): 36-40.

[10] Khan A, Salam A, Khitab U, Tariqkhan M. Pattern of mandibular fractures - a study. Pak Oral Dent J 2009; 29(2): 221-4.
[11] Khan S, Khan M, Khan A, Murtaza B, Maqsood A, Ibrahim W, Ahmed W. Etiology and pattern of maxillofacial injuries in the armed forces of Pakistan. J College of Physc.and Surg.Pak 2007; 17(2): 94-7

[12] Sojat AJ, Meisami T, Sandor GK, Clokie CM. The epidemiology of mandibular fractures treated at the Toronto General Hospital: A review of 246 cases. J Can Dent Assoc 2001; 67 (11): 640-4.

[13] Ansari SR, Khitab U, Qayyum Z, Khattak A. Retrospective analysis of 268 cases of fractures of mandible. Pak Oral Dent J. 24(2): 135-138.

[14] Abbas I, Ali K, Mirza YB (2003) Spectrum of mandibular fractures at a tertiary care dental hospital in Lahore. J Ayub Med Coll Abbottabad. 15(2): 12-4

[15] Shayyab, M, Alsoleihat F, Ryalat S, Khraisat A. Trends in the pattern of facial fractures in different countries of the world. Int J Morphol 2012; 30(20): 745-56.

[16] Dongas P, Hall GM. Mandibular fracture patterns in Tasmania, Australia. Aust Dent J 2002; 47(2): 131-7.

[17] Kamulegeya A, Lakor F, Kabenge K. Oral and maxillofacial fractures seen at a Ugandan tertiary hospital: a six-month prospective study. Clinics 2009; 64(9): 843-8.

[18] Kish L Survey sampling. John Wiley and sons, Inc. New York, 1965.

[19] Krleža-Jerić K, Lemmens T. 7th Revision of the Declaration of Helsinki: Good News for the Transparency of Clinical Trials. 2009; Available at: http://wwwncbinlmnihgov/pmc/articles/ PMC2681053/ [Cited January 12 2018]

[20] Al-Khateeb T, Abdullah FM. Craniomaxillofacial injuries in the United Arab Emirates: A retro spective study. J Oral Maxillofac Surg 2007; 65(6): 1094-101.

[21] Oikarinen K, Schutz P, Thalib L, Sándor GK, Clokie C, Meisami T. Differences in the etiology of mandibular fractures in Kuwait, Canada, and Finland. Dent Traumatol 2004; 20(5): 241-5.

[22] Elgehani RA, Orafi MI. Incidence of mandibular fractures in Eastern part of Libya.Med Oral Pathol Cir Bucal 2009;14 (10): 529-32. 
Etiology and Pattern of Mandibular Fractures among Patients Attending Oral and Maxillofacial Surgery Unit in Mulago Hospital, Uganda: A Cross-Sectional Study

[23] Grace NG. Evaluation of Mandibular fractures in a tertiary Military hospital.Phillipines J Otolaryngol Head and Neck Surg 2011; 26(1): 16-20.

[24] Zaleckas L, Drobnys P, Rimkuvienė J. Incidence and etiology of mandibular fractures treated in Vilnius University Hospital Žalgiris clinic, Lithuania. Acta Med Lit 2013; 20(1): 53-60.

[25] Bither S, Mahindra U, Halli R, Kini Y. Incidence and pattern of mandibular fractures in rural population: a review of 324 patients at a tertiary hospital in Loni, Maharashtra, India. Dent Traumatol 2008 ; 24 (4): 468-70.

[26] Chandra Shekar BR, Reddy C A five year retrospective statistical analysis of maxillofacial injuries in patients admitted and treated at two hospitals of Mysore city. Indian J Dent Res 2008;19(4): 304-8.
[27] Mesgarzadeh AH, Shahmfar M, Azar SF, Shahmfar J. Analysis of he pattern of Maxillofacial Fractures in northwestern region of Iran. J Emerg Trauma Shock 2011; 4(1): 48-56.

[28] Desai J, Lownie JF, Cleaton-Jone P. Prospective audit of Mandibular fractures at Charlotte Makeke Johannesburg Academic Hospital. S Afr J Surg 2010;48(4): 122-6.

[29] Bormann KH, Wild S, Gellrich NC, Kokemüller H, Stühmer C, Schmelzeisen R, Schön R. Five year retrospective study of mandibular fractures in Freiburg, Germany: incidence, etiology, treatment, and complications. J Oral Maxillofac Surg 2009; 67(6): 1251-5.

[30] Tamgadge PB, Kalbande A. Prevalence of madibular fractures in Yavatmal District. Int J Sci Res 2013; 2(5): 479-480.

Citation: Patrick Mpiima, Arabat Kasangaki, Eriab Nkamba, Charles Mugisha Rwenyonyi. Etiology and Pattern of Mandibular Fractures among Patients Attending Oral and Maxillofacial Surgery Unit in Mulago Hospital, Uganda: A Cross-Sectional Study. Archives of Dentistry and Oral Health. 2018; 1(1): 14-21.

Copyright: (C) 2018 Patrick Mpiima, Arabat Kasangaki, Eriab Nkamba, Charles Mugisha Rwenyonyi. This is an open access article distributed under the Creative Commons Attribution License, which permits unrestricted use, distribution, and reproduction in any medium, provided the original work is properly cited. 